\title{
Effect of Salt Spray on Six Ornamental Species
}

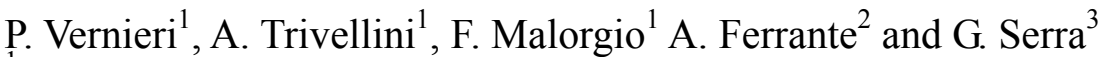 \\ ${ }^{1}$ Dept. Biologia delle Piante Agrarie, University of Pisa, Italy \\ ${ }^{2}$ Dept. Produzione Vegetale, Università degli Studi di Milano, Italy \\ ${ }^{3}$ Sant'Anna School of Advanced Studies, Pisa, Italy
}

Keywords: chlorophyll, coastal, fluorescence, landscape, salt, marine aerosol

\begin{abstract}
Marine aerosol strongly affects the growth and development of urban, garden and landscape plants. The few studies available are focused on the sodium chloride effect on plant growth, usually applied in the irrigation water or substrate media. No information is available on responses of plants to marine aerosol. Therefore, the aim of this work was to evaluate the physiological responses of some species to sea water nebulisation treatment. Species were selected among those that are commonly used along the seaside and among those that might be potentially used. Plants were bought from local nursery and species used were: Acacia cultriformis, Callistemon citrinus, Carissa edulis microphylla, Gaura lindheimeri, Jasminum sambac, Westringia fruticosa. Plants were placed in randomised block in greenhouse and treated once a day for 5-10 seconds with sea water or irrigation water (control) using a nebulisation system.

The effect of marine aerosol was studied by monitoring leaf chlorophyll $a$ fluorescence, chlorophyll content, and leaf area damage by image analysis.

Results were different among species. The effect of treatment was represented by leaf necrosis, reduction of chlorophyll and chlorophyll a fluorescence. The resistant species was Westringia fruticosa, while the intolerant species were $A$. cultriformis and $G$ lindheimeri. Intermediate behaviour was observed in the other species.
\end{abstract}

\section{INTRODUCTION}

Plants grown along the seaside are modelled by marine aerosol and wind that induce severe stress altering the physiology and metabolism. The most common plant responses to saline water are growth reduction, chlorophyll reduction, leaf damage (necrosis), less production of flowers and seeds (Cheplick and Demetri, 1999). The leaf ultrastructure of plants exposed to salt spray is deeply affected with alteration of chlorophast morphology and starch grains disappear or are strongly reduced (SànchezBlanco et al., 2004). In the seaside environment plants underwent a severe genetic selection. Screening experiments using 29 species showed that the most tolerant species were those associated with the coastal habitat (Sykes and Wilson, 1988). The identification of ornamental plants resistant to saline aerosol has great interest for improving the attractiveness of touristic areas and the quality of seaside public and private green areas.

The visual appearance must be guaranteed during the summer period, especially in the touristic areas. The turnover of ornamental species available in the flower market is very high, therefore it is useful to identify rapid tools for screening the plant resistance to marine aerosol in seaside environments. Among the non destructive measurements the chlorophyll a fluorescence has been proved to identify and quantify the plant stresses (Strasser et al., 1995).

The aim of this work was to study the effect of marine aerosol on leaf health status of different ornamental species. Moreover, chlorophyll $a$ fluorescence has been evaluated for rapid identification ornamental shrubs tolerance or sensitivity to salt spray. 


\section{MATERIALS AND METHODS}

\section{Plant Materials}

Plants were bought in local nursery and species used were: Acacia cultriformis Cunn. ex G. Don, Callistemon citrinus (Curtis) Skeels, Carissa edulis var. microphylla Pichon, Gaura lindheimeri Engelm. \& A. Gray, Jasminum sambac (L.) Ait., Westringia fruticosa (Willd.) Druce. Plants were cultivated in greenhouse and daily treated for 5-10 seconds with sea water or irrigation water (control) for 6 weeks using a simple mist system for propagation.

The experimental was set up as a randomized block design with 5 replications.

\section{Chlorophyll Content and Chlorophyll $a$ Fluorescence}

The chlorophyll content was in vivo colorimetrically measured using a nondestructive instrument (CL-01, Hansatech, UK). It was measured after 63 days of exposure to marine aerosol and 10 leaves randomly were used for measurements. Chlorophyll $a$ fluorescence transients were determined on dark adapted leaves kept for 30 min at room temperature, using a portable Handy PEA (Hansatech, UK). The measurements were taken on the leaf surface of 5 leaves ( $4 \mathrm{~mm}$ diameter) exposed to an excitation light intensity (ultra-bright red LEDs with a peak at $650 \mathrm{~nm}$ ) of $3000 \mu \mathrm{mol}$ $\mathrm{m}^{-2} \mathrm{~s}^{-1}\left(600 \mathrm{~W} \mathrm{~m}^{-2}\right)$ emitted by three diodes. Leaf fluorescence detection was measured by fast response PIN photodiode with RG9 long pass filter (Hansatech, technical manual). The parameters measured were Fo, Fm and Fv/Fm. The Fo represents the fluorescence level when the plastoquinone electron acceptor pool $(\mathrm{Qa})$ is fully oxidised. Fm represents the fluorescence level when Qa is transiently fully reduced. The Fv/Fm ratio represents the maximum quantum efficiency of photosystem II, the Fv is the variable fluorescence (Fm-Fo).

\section{Leaf Damage Analysis}

Leaf damage was measured as percentage of total area using the image processing and analysis program UTHSCSA ImageTool ver. 3 (http://ddsdx.uthscsa.edu/dig/ itdesc.html). Image analysis was performed after 63 days of exposure to marine aerosol and 5 leaves were used for each species.

\section{RESULTS AND DISCUSSION}

At the end of the experimental period all species exposed to marine water spray showed a drastic reduction of chlorophyll content ranging from 20-66\%, with the exception of Acacia cultriformis and Gaura lindheimeri, whose leaves were completely disseccated after 3 weeks (Table 1). Leaves of treated G. lindheimeri were completely desiccated after 3 weeks of treatment, but after 5 weeks new sprouts came out and were rich in chlorophyll and anthocyanins (data not shown). The Carissa edulis var. microphylla and Jasminum sambac showed the highest chlorophyll content and the strongest reduction. The Westringia fruticosa had the lowest chlorophyll content and showed intermediate chlorophyll losses. The chlorophyll reduction is a common symptom of saline stress in plants. In rock-rose plants the chlorophyll concentration in leaves increased at low sea aerosol concentrations and then after a certain threshold the chlorophyll content declined (Sánchez-Blanco et al., 2004). It seems that plant reacts to the stress with an increment of chlorophyll for counteracting the salt stress.

The A. cultriformis and G. lindheimeri showed $100 \%$ leaf necrosis (Fig. 1) while $W$. fruticosa was not affected by marine aerosol during the whole experiment period. $C$. edulis and C. citrinus showed severe leaf damage ranging from $46-50 \%$ of total leaf area. The $J$. sambac, instead, showed a 34\% leaf damage. The leaf necrosis is the result of severe salt stress and older leaves are more susceptible in sensitive plants (Parvaiz and Satyawati, 2008). The effect of marine aerosol is more pronounced under high temperatures and wind. In these conditions the evaporation of water is very fast and salt residue on leaves induces phytotoxicity. 
Chlorophyll a fluorescence parameters were influenced differently in the ornamental species. The Fo was particularly high in C. edulis and J. sambac leaves, with values ranging from 600 to 900 . However, the Fo values were not affected by salt spray treatment. On the contrary, the Fm was strongly influenced by the treatment in $A$. cultriformis and G. lindheimeri, while no significant changes were observed in $W$. fruticosa. The highest Fm values were found in C. edulis among control plants and in $W$. fruticosa (2700) in those exposed to marine aerosol treatment (Table 2). The Fo usually increase during senescence or prolonged stress, while the Fm declines (Petkova et al., 2007).

The maximum yield of PSII (Fv/Fm ratio) decreased after 2-3 weeks in $G$. lindheimeri and A. cultriformis to 0.4-0.5, before leaf necrosis. In the A. cultriformis and G. lindheimeri.Fv/Fo rapidly declined under saline treatment. In $W$. fruticosa the Fv/Fm was not influenced by the salt stress and after 63 days treated plants had higher values than control plants (Fig. 2). The chlorophyll $a$ induction curves have been reported for only three species after 45 days (intermediate data point). Marine aerosol differently affected the leaf chlorophyll $a$ fluorescence (Fig. 3). The C. citrinus and J. sambac that had intermediate tolerance to the salt stress showed a different shape in the induction curve. $W$. fruticosa in both control and treated plants had the same chlorophyll $a$ values (Fig. 3). The Fv/Fm ratio indicates the maximal efficiency of PSII. Leaves of deciduous and evergreen trees that have $\mathrm{Fv} / \mathrm{Fm}$ values ranging from to 0.76 to 0.85 are considered unstressed and healthy (Demmig and Björkman, 1987). The chlorophyll a fluorescence induction curve is a pool of information that are useful for understanding how plants respond to the abiotic stress (Strasser et al., 1995; Maxwell and Johnson, 2000).

\section{CONCLUSIONS}

Results showed that the most sensitive to marine aerosol were A. cultriformis and $G$. lindheimeri. On the contrary, $W$. fruticosa was the most tolerant species, while $J$. sambac, $C$. edulis and $C$. citrinus had intermediate behaviour.

\section{ACKNOWLEDGEMENTS}

This work was supported by the MIPAF with project EcoIdriFlor.

\section{Literature Cited}

Cheplick, G.P. and Demetri, H. 1999. Impact of saltwater spray and sand deposition on the coastal annual Triplasis purpurea (Poaceae). Am. J. Bot. 86(5):703-710.

Demmig, B. and Björkman, O. 1987. Comparison of the effect of excessive light on chlorophyll fluorescence $(77 \mathrm{~K})$ and photon yield of $\mathrm{O} 2$ evolution in leaves of higher plants. Planta 171:171-184.

Maxwell, K. and Johnson, G.N. 2000. Chlorophyll fluorescence - a practical guide. J. Exp. Bot. 51:659-668.

Parvaiz, A. and Satyawati, S. 2008. Salt stress and phyto-biochemical responses of plants - a review. Plant Soil Environ. 54(3):89-99.

Sánchez-Blanco, M.J., Rodrìguez, P., Olmos, E., Morales, M.A. and Torrecillas, A. 2004. Differences in the effects of simulated sea aerosol on water relations, salt content, and leaf ultrastructure of rock-rose plants. J. Environ. Qual. 33:1369-1375.

Strasser, R.J., Srivastava, A. and Govindjee. 1995. Polyphasic chlorophyll a fluorescence transient in plants and cyanobacteria. Photochem. Photobiol. 61:32-42.

Sykes, M.T. and Wilson, J.B. 1988. An experimental investigation into the response of some New Zealand sand dune species to salt spray. Ann. Bot. 62:159-166. 


\section{Tables}

Table 1. Chlorophyll content determined by chlorophyll meter (Hansatech, UK) after 63 days of exposure to marine aerosol. Data are reported as means \pm standard errors $(n=5)$.

\begin{tabular}{lcccccccc}
\hline & A. & C. & \multicolumn{2}{c}{ C. edulis var. } & \multicolumn{2}{c}{ G. } & J. & $W$. \\
& cultriformis & citrinus & \multicolumn{2}{c}{ microphylla } & lindheimeri & sambac & fruticosa \\
\hline & & & dark green & light green & blue & green \\
Control & $21.5 \pm 3.88$ & $52.1 \pm 5.67$ & $153.9 \pm 35.39$ & $48.5 \pm 7.33$ & $3.7 \pm 0.45$ & $9.0 \pm 0.93$ & $82.3 \pm 6.13$ & $5.4 \pm 0.45$ \\
Aerosol M. & - & $41.7 \pm 6.34$ & $52.3 \pm 21.22$ & $18.7 \pm 3.72$ & $12.6 \pm 2.35^{*}$ & - & $27.7 \pm 11.17$ & $3.2 \pm 1.02$ \\
Variation (\%) & & $-20 \%$ & -66 & -60 & $+70^{*}$ & & -66 & -40 \\
\hline
\end{tabular}

*young leaves

Table 2. Fm (maximum fluorescence) of different ornamental species exposed to marine aerosol. Values are means with standard errors.

\begin{tabular}{lcccccccccccc}
\hline & & \multicolumn{1}{c}{ Fm (Mean) } \\
\multicolumn{1}{c}{ Time (d) } & \multicolumn{1}{c}{ Acacia } & \multicolumn{2}{c}{ Callistemon } & \multicolumn{2}{c}{ Carissa } & \multicolumn{2}{c}{ Gaura } & Jasminum & \multicolumn{2}{c}{ Westringia } \\
\hline & Control & Salt & Control & Salt & Control & Salt & Control & Salt & Control & Salt & Control & Salt \\
\hline 10 & 1774 & 1955 & 2418 & 2328 & 2887 & 2311 & 2793 & 2596 & 2940 & 2515 & 2776 & 2913 \\
27 & 1770 & 1836 & 2578 & 1795 & 3199 & 2648 & 3492 & 1684 & 2591 & 2030 & 3539 & 3575 \\
34 & & & 2318 & 1638 & 2988 & 2517 & 2648 & & 2903 & 1662 & 3078 & 3084 \\
45 & & & 2278 & 1969 & 3379 & 2560 & 2365 & & 2567 & 1213 & 2749 & 2742 \\
63 & & & 2384 & 2332 & 2998 & 2090 & 1950 & & 2417 & 2017 & 2677 & 2698 \\
\hline & & & & \multicolumn{1}{c}{ Fm $( \pm$ Standard error, $n=5)$} & & & & \\
\hline 10 & 196.12 & 232.54 & 104.50 & 157.86 & 132.00 & 204.40 & 48.09 & 166.34 & 213.53 & 211.09 & 135.16 & 114.92 \\
27 & 0.00 & 248.07 & 197.07 & 174.54 & 139.96 & 37.13 & 26.11 & 339.78 & 125.47 & 272.80 & 40.28 & 157.89 \\
34 & & & 117.44 & 227.33 & 70.38 & 286.01 & 194.75 & & 142.88 & 311.25 & 350.06 & 133.07 \\
45 & & & 203.32 & 183.74 & 58.71 & 229.92 & 123.56 & & 168.72 & 147.18 & 82.03 & 128.76 \\
63 & & & 100.02 & 81.77 & 63.89 & 133.93 & 267.15 & & 131.49 & 114.72 & 107.75 & 42.62 \\
\hline
\end{tabular}




\section{Figures}

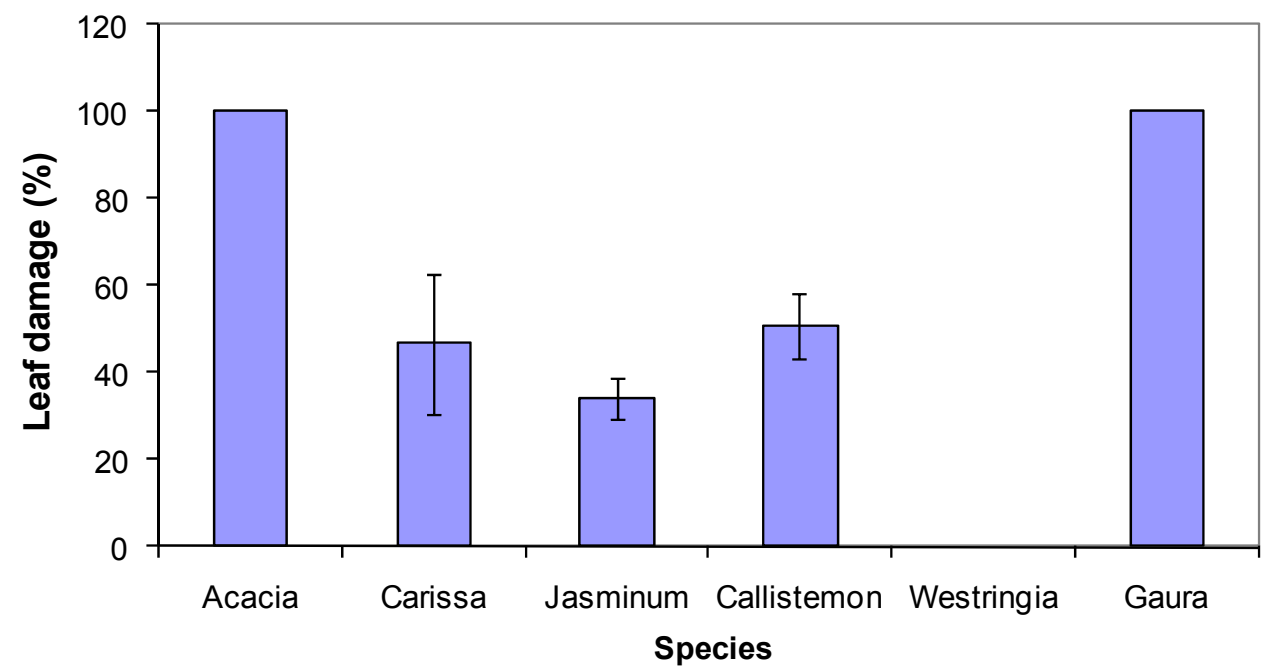

Fig. 1. Leaf damage percentage in different ornamental species exposed to marine aerosol after 63 days. Values are means with standard errors $(n=5)$.

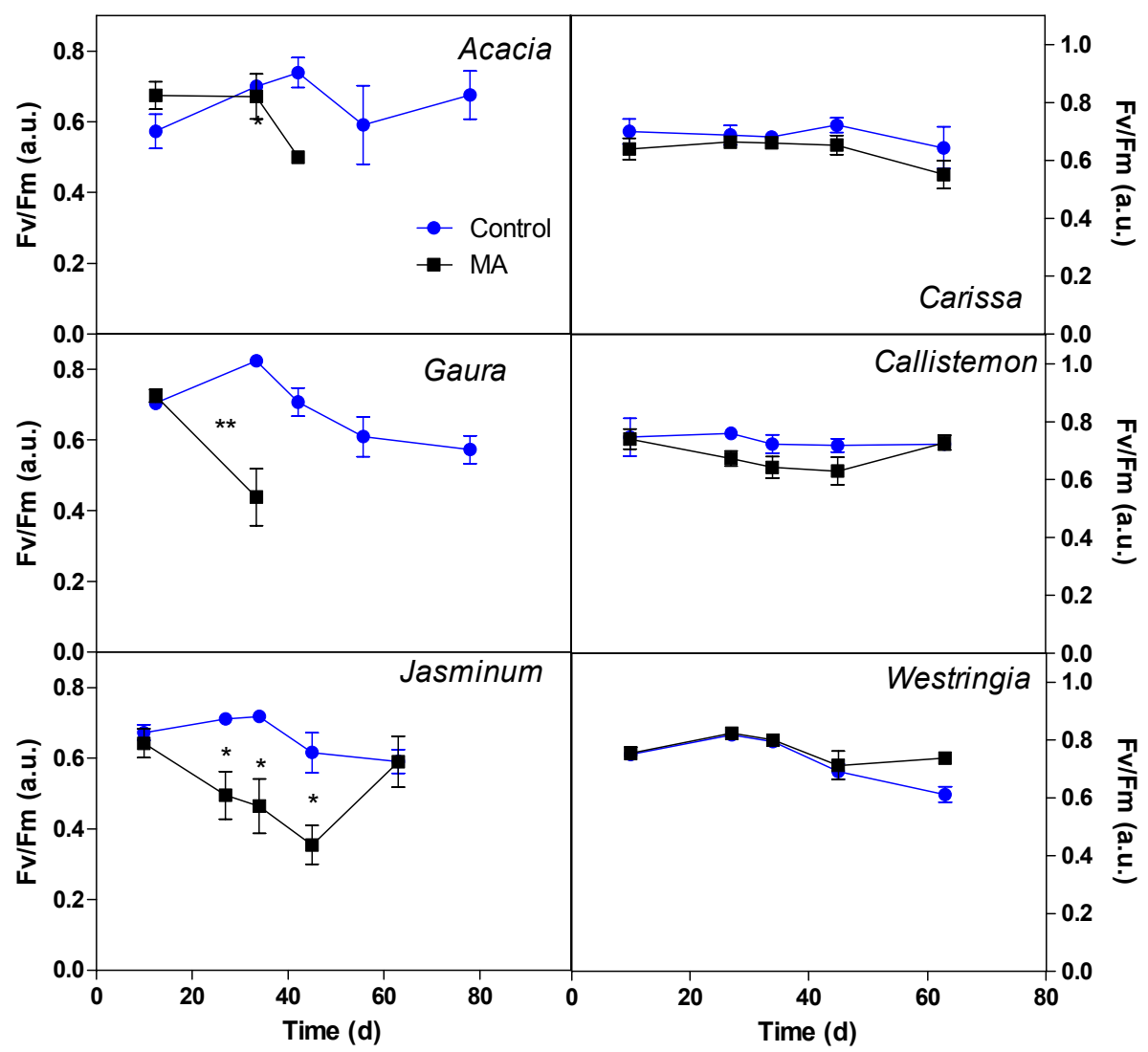

Fig. 2. Fv/Fm ratio (maximum quantum efficiency of photosystem II) values in ornamental species exposed to marine aerosol (MA). Data are means with standard errors $(n=5)$. Differences between control and SWA were determined using $t$-test. Asterisks represent statistical differences, ${ }^{*} \mathrm{P}<0.05, * * \mathrm{P}<0.01$. 


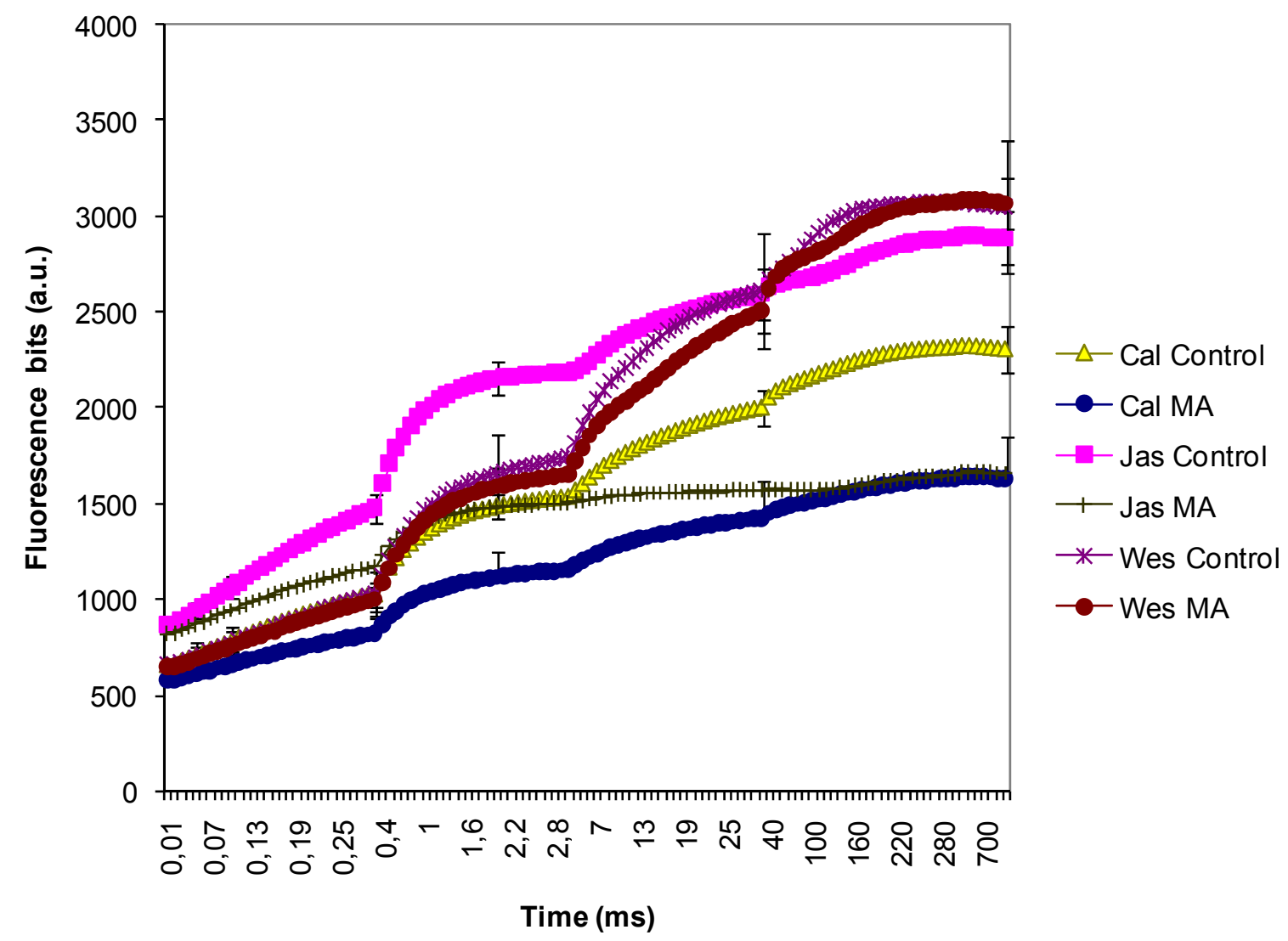

Fig. 3. Chlorophyll a fluorescence induction curves of C. citrinus (Cal), J. sambac (Jas) and $W$. fruticosa (Wes) leaves exposed to marine aerosol (MA). Data are means with standard errors $(n=5)$. 